\title{
Distribution of hydrophilic, amphiphilic and hydrophobic ions at a liquid/liquid interface: a molecular dynamics investigation
}

\author{
Frédéric Berny, Rachel Schurhammer, Georges Wipff* \\ Institut de Chimie, Université Louis Pasteur, UMR CNRS 7551, 4, rue B. Pascal, 67000 Strasbourg, France
}

Received 22 September 1999; accepted 25 November 1999

\begin{abstract}
We report molecular dynamics studies on the interfacial distribution of ionic species of different size, shape and topology at a water/chloroform interface: hydrophilic $\mathrm{K}^{+} \mathrm{Cl}^{-}, \mathrm{K}^{+} \mathrm{SCN}^{-}$and $\mathrm{K}^{+} \mathrm{Pic}^{-}$ions, amphiphilic ammonium $\mathrm{NTMA}^{+}$cations and farnesylphosphate $\mathrm{FPH}^{-}$anions, tetrahedral hydrophobic $\mathrm{AsPh}_{4}^{+}$and $\mathrm{BPh}_{4}^{-}$ions, with different counterions. Contrasted distributions are observed. The $\mathrm{K}^{+} \mathrm{Cl}^{-}$and $\mathrm{K}^{+} \mathrm{SCN}^{-}$ions sit almost exclusively in the water phase, but $\mathrm{SCN}^{-}$is less 'repelled' than $\mathrm{Cl}^{-}$by the interface. The $\mathrm{Pic}^{-}$anions are partly adsorbed at the interface and dissolved in the water phase where they display remarkable $\pi$-stacking interactions. Amphiphilic $\mathrm{NTMA}^{+}$cations or $\mathrm{FPH}^{-}$anions adsorb and dilute at the interface. Less expected is the high surface activity of symmetrical $\mathrm{AsPh}_{4}^{+}$and $\mathrm{BPh}_{4}^{-}$ions, with marked counterion effects. The two ions fully adsorb at the interface in the $\mathrm{AsPh}_{4}^{+} \mathrm{BPh}_{4}^{-}$salt, while in the $\mathrm{Na}^{+} \mathrm{BPh}_{4}^{-}$or $\mathrm{AsPh}_{4}^{+} \mathrm{Cl}^{-}$salts, they display an equilibrium between the organic phase and the interface. Crossed comparisons between the different solutions reveal the important role of counterions on the distribution of a given ionic species. These results are discussed in relation to experimental data. (C) 2000 Elsevier Science S.A. All rights reserved.
\end{abstract}

Keywords: Liquid interfaces; Ion extraction; Molecular dynamics

\section{Introduction}

The interface between two immiscible electrolyte solutions (ITIES) displays peculiar solvation properties, compared to the adjacent liquid phases [1-5]. A precise knowledge of ITIES is of interest in many areas of physical chemistry such as electrochemistry, phase transfer catalysis, drug availability, ion separation by liquid/liquid extraction, liquid chromatography, as well as membranes mimetics. What happens at the surface of water has also important implications in environmental processes or atmospheric pollution. However, microscopic pictures of this very thin boarder are difficult to obtain by experiment. As quoted recently, 'the field is still in its infancy: Little is known about the structure of the interface, and most of our secure knowledge relies on thermodynamics' [6]. Most of the

\footnotetext{
* Corresponding author. Tel.: + 33-388-416 071; fax: + 33-388416104.

E-mail address: wipff@chimie.u-strasbg.fr (G. Wipff)
}

insights come indeed from electrochemical measurements of current, potentials, and surface tension, which give information on the concentration ('activity') of the ions at the interface [7] and on energetic aspects of adsorption and transfer across the interface $[2,8]$. Structural features may be investigated by surface spectroscopy $[9,10]$, X-ray or neutron reflectivity [11], but precise information is rather limited.

Molecular dynamics (MD) or Monte Carlo (MC) [12] simulations techniques, which explicitly account for statistical features of solvation contribute to our understanding of the solution behaviour of ions and provide microscopic pictures in solution. In the early seventies, Clementi performed MC studies of the hydration of ions [13]. In 1983, Impey et al. investigated by MD the solvation and mobility of ions in water [14]. Most of the studies dealt with aqueous solutions, but other solvents (e.g. acetonitrile [15], chloroform [16], methanol, ammonia and methylamine [17], or carbonate solvents [18]) were examined as well. Studies in mixed solvents or at the surface of liquids [19] are less 
common. Pioneering work on ions at aqueous interfaces involves the MC simulations of Torrie and Valleau [20] and of Matsui and Jorgensen [19], the MD studies of Heinzinger et al. [21,22] and those of Benjamin [23]. Excellent accounts can be found in Refs. [24,25]. Layers or micelles of cationic [26] or anionic [27] surfactants have also been extensively studied.

We have been interested in interfaces in the context of liquid/liquid extraction of ions by extractant molecules ('ionophores'). The first simulations revealed that extractant molecules like calixarenes [28,29], cryptands [30], alkyl-phosphates [31], podants [30], crown ethers [32], valinomycine [33], although more soluble in the organic phase ('oil') than in water, strongly adsorb at the water/'oil' interface, instead of spontaneously diffusing from the interface to the oil phase. These conclusions were obtained from different starting configurations, be the solute initially at the boarder between the two liquids, or immersed in one of them, or in completely mixed solutions [34-37]. The investigation of free energy profiles $(\mathrm{PMF}=$ 'potential of mean force') for interface crossing [38] confirmed the high surface activity of the extractants in the uncomplexed as well as in their complexed states. Different types of ions were considered. First, those involved in the extraction process (e.g. $\mathrm{Cs}^{+} / \mathrm{Na}^{+}$extraction by calixarenes [28], uranyl extraction by CMPO [39] or TBP [37], $\mathrm{Sr}^{2+}$ extraction by 18-crown-6 [32] or calixarenes [40]) with different counterions (e.g. $\mathrm{Cl}^{-} / \mathrm{NO}_{3}^{-} /$ $\mathrm{Pic}^{-}$) [28,38,41]. Phospholipids [42], quaternary ammonium cations [35,36], guanidinium ${ }^{+}, \mathrm{AsPh}_{4}^{+}$or $\mathrm{BPh}_{4}{ }^{-}$were also modelled.

In this paper, we present new results obtained at the water/chloroform interface with different electrolyte solutions (see Fig. 1), at concentrations of about $0.1 \mathrm{~mol}$ $1^{-1}$. The $\mathrm{K}^{+} / \mathrm{Cl}^{-}$solution of hydrophilic ions is com-

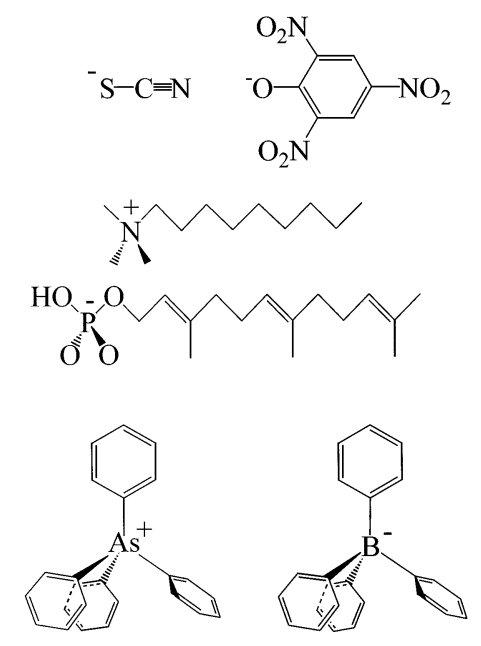

Fig. 1. Simulated molecular ions: $\mathrm{SCN}^{-}, \mathrm{Pic}^{-}, \mathrm{NTMA}^{+}, \mathrm{FPH}^{-}$, $\mathrm{AsPh}_{4}{ }^{+}, \mathrm{BPh}_{4}{ }^{-}$. pared with the $\mathrm{K}^{+} \mathrm{SCN}^{-}$and $\mathrm{K}^{+} \mathrm{Pic}^{-}$solutions containing more chaotropic and less hydrophilic [43] anions. The $\mathrm{Pic}^{-}$anion, which can be followed spectroscopically, is often used in ion extraction systems [44]. Two amphiphilic systems are modelled, $\mathrm{NTMA}^{+} \mathrm{Cl}^{-}$ and $\mathrm{FPH}^{-} \mathrm{Na}^{+}$, containing respectively a quaternary ammonium cation with a linear alkyl chain NTMA $^{+}$ $=$ nonyltrimethylammonium) and a phospholipid with an unsaturated branched hydrocarbon chain $\left(\mathrm{FPH}^{-}=\right.$ farnesylphosphate). $\mathrm{FPH}^{-}$is of interest in the context of formation of primitive biological membranes [45]. $\mathrm{NTMA}^{+}$and $\mathrm{FPH}^{-}$are simulated with hydrophilic counterions $\left(\mathrm{Cl}^{-}\right.$and $\mathrm{Na}^{+}$, respectively). The next salts contain the $\mathrm{AsPh}_{4}^{+}$cation and the $\mathrm{BPh}_{4}^{-}$anion. According to the TATB (tetraphenylarsonium tetraphenylborate) hypothesis, $\mathrm{AsPh}_{4}^{+}$and $\mathrm{BPh}_{4}^{-}$display similar solvation features in any solvent, and should therefore have identical free energies of transfer from water to any solvent [46]. We recently simulated the $\left(\mathrm{AsPh}_{4}{ }^{+} \mathrm{BPh}_{4}^{-}\right)_{1}$ monomeric species [47]. Here, the salt is simulated in more concentrated conditions and the role of counterions is examined in the $\mathrm{Na}^{+} \mathrm{BPh}_{4}{ }^{-}$and $\mathrm{AsPh}_{4}{ }^{+} \mathrm{Cl}^{-}$electrolytes. Finally, we report a 'computer demixing experiment' of a perfectly mixed water-oil solution of $\mathrm{NTMA}^{+} \mathrm{Cl}^{-}$and compare the resulting ion distribution to the one calculated in somewhat different conditions at a preformed interface.

\section{Methods}

The simulations were performed with AMBER5.0 [48] where the potential energy is described by a sum of bond, angle and dihedral deformation energies, and pairwise additive 1-6-12 (electrostatic + van der Waals) interactions between non-bonded atoms. Parameters of $\mathrm{AsPh}_{4}{ }^{+}$and $\mathrm{BPh}_{4}^{-}$are from Ref. [47], while those of $\mathrm{Pic}^{-}$are from Ref. [49]. The $\mathrm{Na}^{+}$and $\mathrm{K}^{+}$parameters are from Åvist [50] and those of $\mathrm{Cl}^{-}$are from Ref. [51]. The charges of $\mathrm{NTMA}^{+}$and $\mathrm{FPH}^{-}$are given in Fig. 2. NTMA' $^{+}$was modelled 'by hand' to sketch its amphiphilic character, i.e. with $\mathrm{a}+1$ charge on the polar head and a null charge on all atoms of the $\mathrm{C}_{7} \mathrm{H}_{15}$ chain. The $\mathrm{FPH}^{-}$charges were obtained with SPARTAN [52] from a 6-31G* geometry optimization and ESP charge fitting. As solvent models, we used TIP3P for water [53] and OPLS for chloroform [54], fitted on the pure liquid properties. The simulated solvent systems and simulation conditions are summarized in Table 1. All $\mathrm{C}-\mathrm{H}, \mathrm{O}-\mathrm{H}$ and solvent $\mathrm{H} \cdots \mathrm{H}, \mathrm{C}-\mathrm{Cl}$ and $\mathrm{Cl} \cdots \mathrm{Cl}$ 'bonds' were constrained with SHAKE [48], using a time step of $2 \mathrm{fs}$. The temperature was monitored by coupling the system to a thermal bath at the reference temperature with a relaxation time of $0.4 \mathrm{ps}$. 

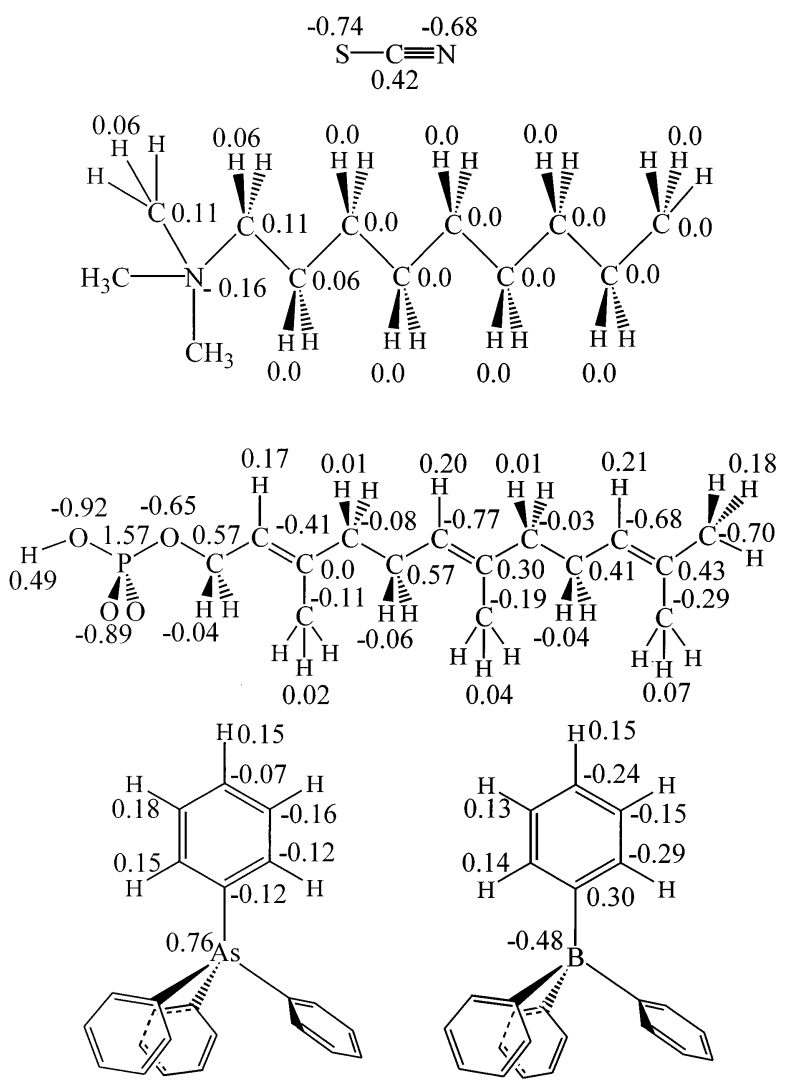

Fig. 2. Atomic charges and atom types used to simulate $\mathrm{SCN}^{-}$, $\mathrm{NTMA}^{+}, \mathrm{FPH}^{-}, \mathrm{AsPh}_{4}{ }^{+}$and $\mathrm{BPh}_{4}{ }^{-}$.

The evaluation of the potential energy in electrolytes is a difficult task due to the electrostatic component. In principle, it would be desirable to account for nonbonded interactions at and beyond the cutoff distance used to truncate the electrostatic interactions $[55,56]$. The reaction field (RF) [57] or the Ewald [58] summation methods, developed for that purpose, imply a $3 \mathrm{D}$ periodic representation of the system, inconsistent with the $2 \mathrm{D}$ periodicity of the interface. As the corresponding $2 \mathrm{D}$ Ewald $[22,59]$ is presently not available in AMBER, we present the results obtained from standard calculations.

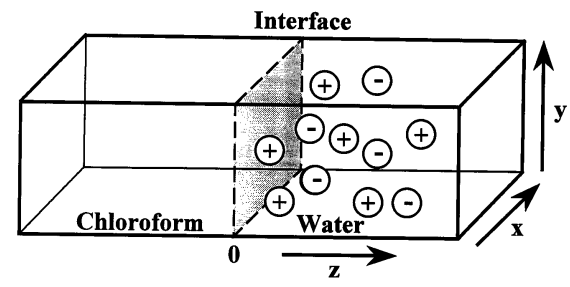

Fig. 3. The water/chloroform interface with ionic solutes.

Some tests with 3D Ewald (PME approximation $[48,60]$ ) are also reported for the $\mathrm{AsPh}_{4}{ }^{+} \mathrm{BPh}_{4}{ }^{-}$salt.

The water/chloroform interface has been built as indicated in Ref. [34,38], starting with two adjacent boxes of pure water and chloroform, respectively (Fig. 3). The solutes were initially placed at the interface, equally shared between the two solvent phases. After energy minimization, the MD was run at $300 \mathrm{~K}$. Some systems were represented with $3 \mathrm{D}$ periodic boundary conditions, while for others periodicity was applied along the $X$ and $Y$ directions only, using a restraining potential at the $Z$ boundaries to avoid evaporation of solvent molecules (see Table 1 and Ref. [36]). Thus, the 3D systems correspond to alternating slabs of water and chloroform separated by one water/chloroform interface, while the 2D systems correspond to a single water/chloroform interface and to two air/liquid interfaces.

The protocol of the demixing simulation of the $\mathrm{NTMA}^{+} \mathrm{Cl}^{-}$binary solution, similar to the one described in Ref. [34], follows three steps. (i) First, 100 ps equilibrium simulation at $300 \mathrm{~K}$ with the solute placed at the water/chloroform interface to ensure that solvent densities in the bulk region are correct. (ii) Then, a simulation at $500 \mathrm{~K}$ at constant volume using biased potentials, in order to mix the solvents. (iii) After energy minimization, the demixing simulation starts, resetting the temperature at $300 \mathrm{~K}$ and all charges at their reference values.

The results have been analyzed as described in Ref. [38]. The 'stoichiometry' of the systems is given in Table 1. For instance, $\left(\mathrm{K}^{+} \mathrm{SCN}^{-}\right)_{10}$ means that ten $\mathrm{K}^{+} \mathrm{SCN}^{-}$ions are simulated per solvent box. The

Table 1

Simulation conditions at the interface ${ }^{a}$

\begin{tabular}{|c|c|c|c|c|c|c|}
\hline Solute & Box size $\left(\AA^{3}\right)$ & Solvent $\mathrm{N}_{\mathrm{chl}}+\mathrm{N}_{\mathrm{wat}}$ & $2 \mathrm{D} / 3 \mathrm{D}$ & Cutoff & Time (ns) & Mol 1-1 \\
\hline$\left(\mathrm{K}^{+} \mathrm{Cl}^{-}\right)_{20}$ & $34 * 32 *(36+36)$ & $279+1237$ & $2 \mathrm{D}$ & 12.5 & 1 & 0.43 \\
\hline$\left(\mathrm{K}^{+} \mathrm{SCN}^{-}\right)_{10}$ & $50 * 42 *(30+30)$ & $467+2048$ & $2 \mathrm{D}$ & 12.5 & 1 & 0.13 \\
\hline$\left(\mathrm{Na}^{+} \mathrm{FPH}^{-}\right)_{10}$ & $44 * 47 *(45+34)$ & $645+2264$ & $2 \mathrm{D}$ & 12.5 & 1 & 0.10 \\
\hline$\left(\mathrm{NTMA}^{+} \mathrm{Cl}^{-}\right)_{10}$ & $52 * 42 *(39+32)$ & $581+2208$ & $2 \mathrm{D}$ & 12.5 & 1 & 0.11 \\
\hline$\left(\mathrm{AsPh}_{4}^{+} \mathrm{BPh}_{4}^{-}\right)_{9}$ & $37 * 37 *(47+37)$ & $419+1512$ & $3 \mathrm{D}$ & 13 & 1 & 0.13 \\
\hline$\left(\mathrm{NTMA}^{+} \mathrm{Cl}^{-}\right)_{10 \text { demixing }}$ & $52 * 42 * 71$ & $581+2208$ & $3 \mathrm{D}$ & 12.5 & 1 & 0.11 \\
\hline
\end{tabular}

\footnotetext{
${ }^{\text {a }}$ Box size $\mathrm{V}_{x} * \mathrm{~V}_{y} *\left(\mathrm{~V}_{z-\text { chlor }}+\mathrm{V}_{z-\text { wat }}\right)$. Number of chloroform and water molecules. Periodicity (2D/3D) of the simulated system, cutoff distance and simulated time. Cation concentration with respect to the box size.
} 
percentage of species 'near the interface' was calculated from the statistical average of these species which are within a distance of $7 \AA$ from the interface. According to solvent density curves, this distance corresponds to about half of the interfacial width.

\section{Results}

During the simulations, some systems remained close to their initial configuration, while others underwent spectacular reorganization. In all cases, the solutes and the solvents display dynamic features, as does the interface. This is why the results have been analyzed with respect to the plane of the interface, defined by the $Z$-coordinate of the intersection of the solvent density curves, calculated every 0.2 ps. In the following, we mainly focus on the ion distributions, illustrated by typical snapshots of the last (generally $1 \mathrm{~ns}$ ) configurations, by cumulated views and density curves obtained from the last 200 ps. The solvent density profiles are similar with all systems, and similar to those obtained for the corresponding neat interface [29]. On the average, the interface is narrow and sharp, about $10-14 \AA$ width, which corresponds to the size of a few fluctuating solvent molecules. Beyond this region, with a few exceptions, no solvent mixing is observed. Instantaneously, however, the water surface and the oil surface are not flat, but display protuberances of up to $7 \AA$, corresponding to the solvent granularity. Some examples are given in Fig. 4 for the $\mathrm{K}^{+} \mathrm{Cl}^{-}$and $\mathrm{AsPh}_{4}{ }^{+}$ $\mathrm{BPh}_{4}{ }^{-}$solutions. It can be seen how the shape of the surface changes in less than $2 \mathrm{ps}$, and how molecules adsorbed at the interface (here, $\mathrm{AsPh}_{4}{ }^{+}$and $\mathrm{BPh}_{4}{ }^{-}$) imprint their shape at the water surface. The 'water fingers' are somewhat longer with the $\mathrm{AsPh}_{4}{ }^{+} \mathrm{BPh}_{4}{ }^{-}$ than with the $\mathrm{K}^{+} \mathrm{Cl}^{-}$solution.

\subsection{Salts of two hydrophilic ions $\left(\mathrm{K}^{+} \mathrm{Cl}^{-}, \mathrm{K}^{+} \mathrm{SCN}^{-}\right.$} and $\mathrm{K}^{+} \mathrm{Pic}^{-}$) at the interface

The simulation of the $\left(\mathrm{K}^{+} \mathrm{Cl}^{-}\right)_{20},\left(\mathrm{~K}^{+} \mathrm{SCN}^{-}\right)_{10}$ and $\left(\mathrm{K}^{+} \mathrm{Pic}^{-}\right)_{10}$ solutions started with a grid of alternating ions located right at the interface. Dissolution took
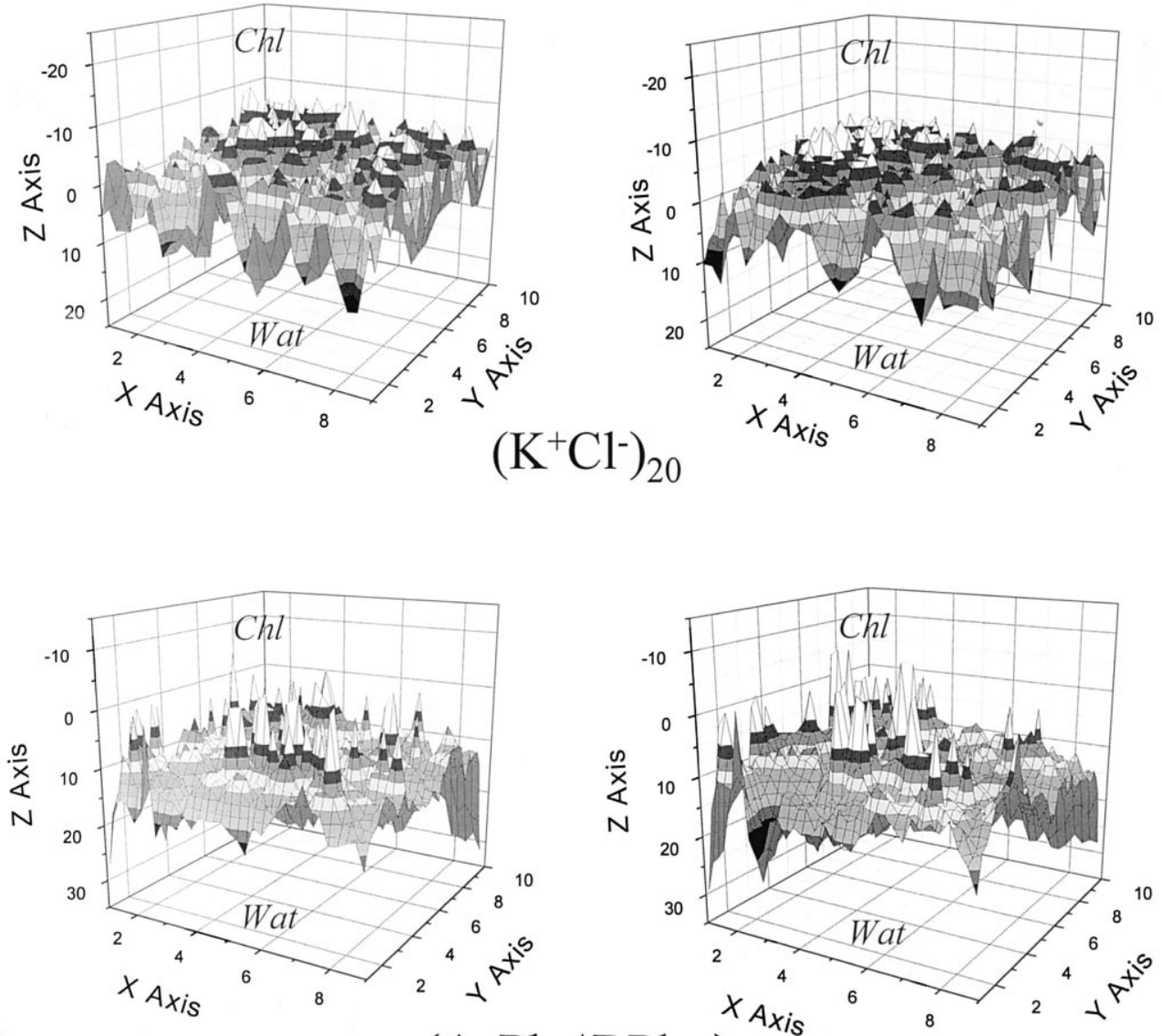

$\left(\mathrm{K}^{+} \mathrm{Cl}^{-}\right)_{20}$

$\left(\mathrm{AsPh}_{4}{ }^{+} \mathrm{BPh}_{4}^{-}\right)_{9}$

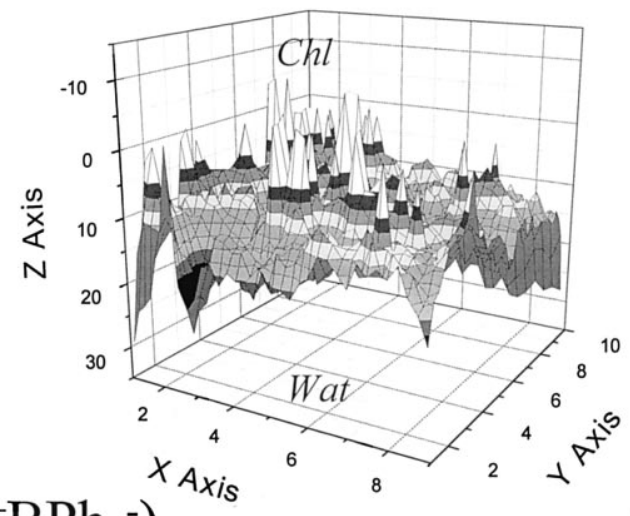

500 ps

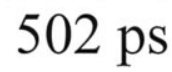

Fig. 4. Instant water surface at the water/chloroform interface: $\left(\mathrm{K}^{+} \mathrm{Cl}^{-}\right)_{20}$ and $\left(\mathrm{AsPh}_{4}^{+} \mathrm{BPh}_{4}^{-}\right)_{9}$ solutions at 500 and 502 ps. 
place readily, driven by hydration forces, leading to noticeable differences in ion distributions (Fig. 5). After MD equilibration, the $\mathrm{K}^{+} \mathrm{Cl}^{-}$solution, the cation and anion distributions are nearly superposed and display a marked peak at the center of the water slab. Only $7 \%$ of each ion are within $7 \AA$ from the interface. In the $\mathrm{K}^{+}$ $\mathrm{SCN}^{-}$solution, the anions are more equally diluted in the water phase, some of them (about 17\%) being close to the interface. Thus, the thiocyanate anion, like perchlorate [35], which sit on the right hand side of the Hofmeister series $\left(\mathrm{SO}_{4}^{2-}>\mathrm{F}^{-}>\mathrm{Cl}^{-}>\mathrm{I}^{-}=\mathrm{ClO}_{4}^{-}>\right.$ $\mathrm{SCN}^{-}$[61]) displays some surface activity, despite its low electronic asymmetry. These trends are consistent with changes in surface tension at the air/water interface [62-64], which displays obvious analogies with the oil-water interface. The orientation of the $\mathrm{SCN}^{-}$anions is more or less random in the water slab, but becomes more parallel to the average solvent separation surface in the interfacial region (Fig. 5).

The $\mathrm{K}^{+} \mathrm{Pic}^{-}$solution behaves similar to the $\mathrm{Cs}^{+}$ $\mathrm{Pic}^{-}$one [37] and displays two remarkable features. First, there is an important concentration (about 42\%) of $\mathrm{Pic}^{-}$anions near the water/chloroform border. Second, there are marked 'attractions' between $\mathrm{Pic}^{-}$anions in the water phase. Despite their mutual electrostatic repulsions, the anions form $\pi$-stacking arrangements which dynamically evolve from dimers up to a pentamer, surrounded by $\mathrm{K}^{+}$counterions. As shown by Troxler and Wipff, stacking mostly results from hydrophobic interactions, as it is not observed in non-aqueous solvents like acetonitrile [49] or chloroform [65]. As the simulated $\mathrm{K}^{+} \mathrm{Pic}^{-}$concentration is above the solubility limit in water (about $0.15 \mathrm{~mol}^{-1}$ ), such stacking may be viewed as the early stages of crystal nucleation near the interface. Analogies with solid state structures are given in Ref. [49].

\subsection{Salts of amphiphilic ions $\left(\mathrm{Na}^{+} \mathrm{FPH}^{-}\right.$and $\mathrm{NTMA^{+ }}$ $\mathrm{Cl}^{-}$) at the interface}

As expected, ions of amphiphilic topology sit at the boundary region between the two liquids, with the polar head solvated by water and the tail mostly solvated by chloroform (Fig. 6). In both cases, the accompanying hydrophilic counterions $\mathrm{Na}^{+}$or $\mathrm{Cl}^{-}$are completely immersed in water. There are however distinct distributions of the $\mathrm{NTMA}^{+}$cations, compared to the $\mathrm{FPH}^{-}$anions after a same simulated time (1 ns). A marked proportion of $\mathrm{NTMA}^{+}$cations (about 30\%) has moved from the water/chloroform interface across the water phase, to adsorb at the water/air interface. About $10 \%$ are also found near the center of the water slab, indicating that these cations are more soluble in water than in the organic phase. In the $\mathrm{FPH}^{-}$solution, at least $85 \%$ of the anions remained at the interface where they diluted. One $\mathrm{FPH}^{-}$molecule oscillated several times between the interface and the water phase. In contrast to the $\mathrm{NTMA}^{+}$system, no $\mathrm{FPH}^{-}$molecule migrated deep enough in water to adsorb at the water/ air interface, likely because the hydrocarbon chain of $\mathrm{FPH}^{-}$is more hydrophobic than the chain of $\mathrm{NTMA}^{+}$.

In relation with the different distributions of amphiphilic ions, one also notices some different distribution of their counterions (Fig. 6). Although anions are thought to be more surface active than cations of same size $[66,80]$, ones finds more $\mathrm{Na}^{+}$cations (about 40\%) than $\mathrm{Cl}^{-}$anions (about 20\%) near the interface, due to the attractions with adsorbed amphiphilic ions.

In both systems, the alkyl chains seem too small to attract the ions in the oil phase and to compete with the hydration forces of the polar head and with the attractions of accompanying counterions. As a result, the centers of the polar heads $\left(\mathrm{N}\right.$ atom of $\mathrm{NTMA}^{+}$or $\mathrm{P}$ atom of $\mathrm{FPH}^{-}$) sit somewhat on the water side of the interface, and the alkyl chains display important contacts with water. The corresponding average water-head and water-chain interaction energies are -50 and -20 $\mathrm{kcal} / \mathrm{mol}$ per $\mathrm{NTMA}^{+}$and $-200^{1}$ and $+17 \mathrm{kcal} / \mathrm{mol}$ per $\mathrm{FPH}^{-}$ion. Noteworthy also is the $\mathrm{Cl}^{-}$anion distribution in the $\mathrm{NTMA}^{+} \mathrm{Cl}^{-}$, compared to the $\mathrm{K}^{+}$ $\mathrm{Cl}^{-}$solution. The anions are more concentrated near the interface with $\mathrm{NTMA}^{+}$(about $20 \%$ ) than with $\mathrm{K}^{+}$ counterions $(7 \%)$, as a result of the positive surface potential created by $\mathrm{NMTA}^{+}$.

\subsection{Salts containing hydrophobic ions $\left(\mathrm{AsPh}_{4}^{+}\right.$ $\left.\mathrm{BPh}_{4}^{-}\right)_{9},\left(\mathrm{Na}^{+} \mathrm{BPh}_{4}^{-}\right)_{9}$ and $\left(\mathrm{AsPh}_{4}^{+} \mathrm{Cl}^{-}\right)_{9}$ at the interface}

In the $\left(\mathrm{AsPh}_{4}{ }^{+} \mathrm{BPh}_{4}{ }^{-}\right)_{9},\left(\mathrm{Na}^{+} \mathrm{BPh}_{4}{ }^{-}\right)_{9}$ and $\left(\mathrm{AsPh}_{4}{ }^{+}\right.$ $\left.\mathrm{Cl}^{-}\right)_{9}$ simulated systems, the ions formed initially two layers in the plane of the interface, with two $3 \times 3$ grids of like-ions. After $1 \mathrm{~ns}$ of simulation (Fig. 7), different ion distributions were observed, demonstrating the high surface activity of $\mathrm{AsPh}_{4}{ }^{+}$and $\mathrm{BPh}_{4}{ }^{-}$. In the $\left(\mathrm{AsPh}_{4}{ }^{+}\right.$ $\left.\mathrm{BPh}_{4}^{-}\right)_{9}$ system, the two layers collapsed into a single one. All $\mathrm{AsPh}_{4}{ }^{+}$and $\mathrm{BPh}_{4}{ }^{-}$ions, although more soluble in chloroform than in water, moved to the plane of the interface, oscillating a few Angströms away from their equilibrium position, instead of spontaneously diffusing to the chloroform phase. As a result, the interface is electrically neutral and no ion sits in the adjacent liquids. Cation-anion attractions at the interface lead to dynamic exchange beween $\pi-\pi$ stacking interactions (parallel aromatic rings) and quadrupolequadrupole interactions (perpendicular rings), reminis-

\footnotetext{
${ }^{1}$ This energy includes the contribution of the four phosphate oxygen atoms of the polar head.
} 

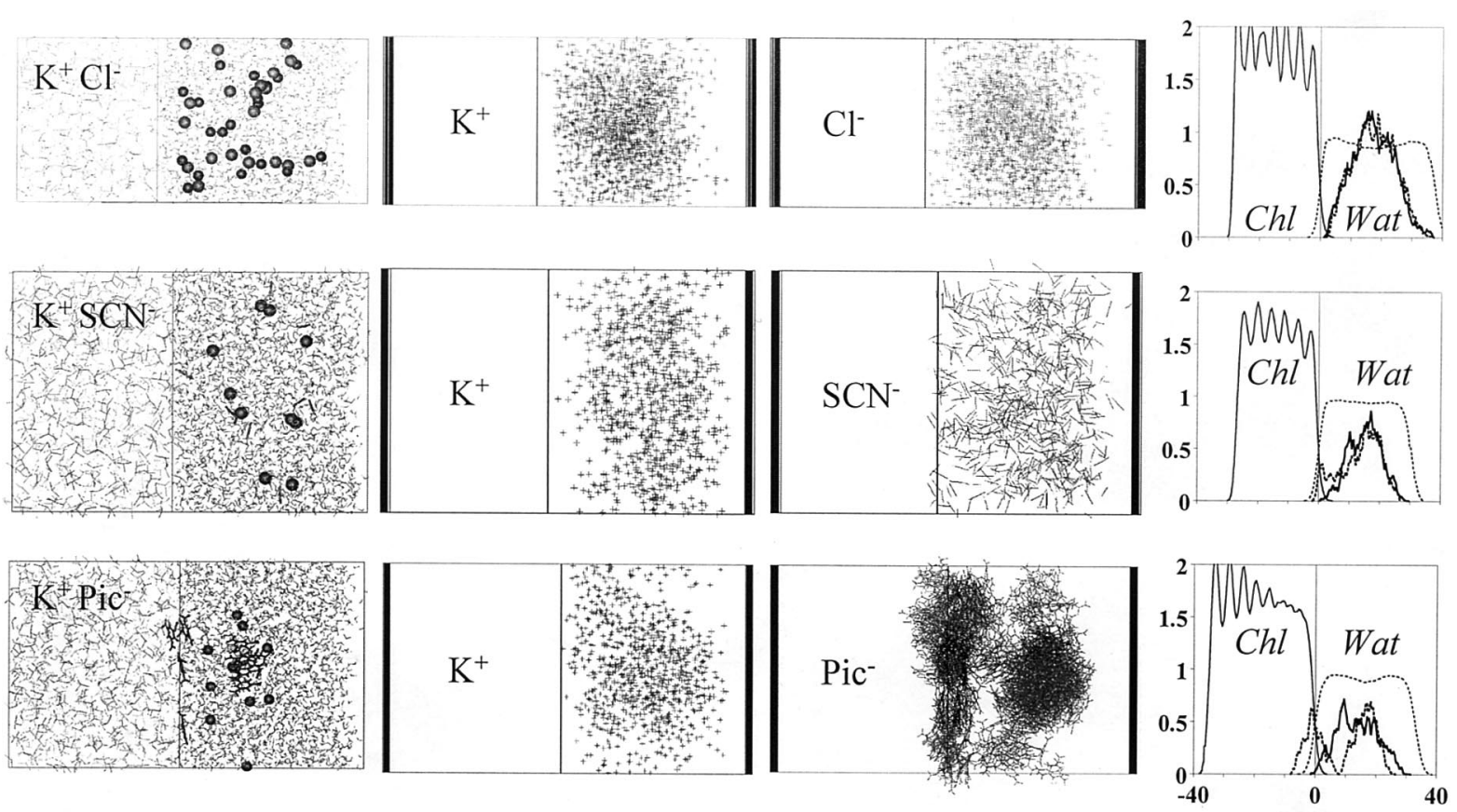

Fig. 5. The $\left(\mathrm{K}^{+} \mathrm{Cl}^{-}\right)_{20},\left(\mathrm{~K}^{+} \mathrm{SCN}^{-}\right)_{10}$ and $\left(\mathrm{K}^{+} \mathrm{Pic}^{-}\right)_{10}$ salts at the interface. From left to right: Snapshots at 1 ns, cumulated views of the cations and of the anions and density profiles of the solvents, cations (full line) and anions (dotted lines) calculated during the last 200 ps. The interface corresponds to $z=0.0$.
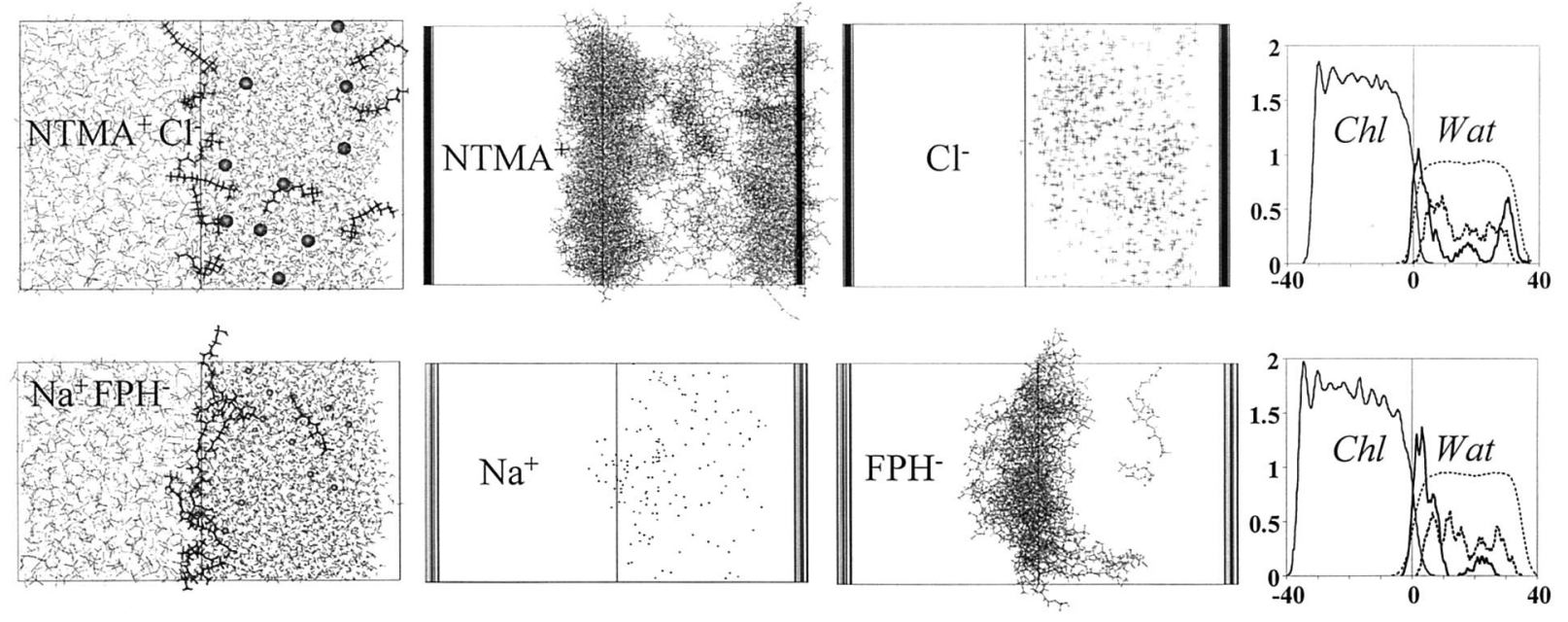

Fig. 6. The $\left(\mathrm{NTMA}^{+} \mathrm{Cl}^{-}\right)_{10}$ and $\left(\mathrm{Na}^{+} \mathrm{FPH}^{-}\right)_{10}$ salts at the interface. See Figure 5 for definitions.

cent of patterns observed in solid state structures $[67,68]$. This interfacial situation is similar to the one calculated in less concentrated conditions [47]. At the interface, both ions still enjoy attractions with water (of about $15 \mathrm{kcal} / \mathrm{mol}$ per $\mathrm{AsPh}_{4}{ }^{+}$cation and $40 \mathrm{kcal} / \mathrm{mol}$ per $\mathrm{BPh}_{4}^{-}$anion), i.e. about 15 and $30 \%$, respectively of their total interaction energies with bulk water [47]. We checked that this distribution does not artefactually result from the neglect of long range interactions. For this purpose, a MD simulation was re-run for $1 \mathrm{~ns}$, using the PME Ewald correction. The final distribution
(Fig. 8) turned out to be indeed nearly identical to the one obtained without Ewald.

The calculated surface activity is fully consistent with recent experimental results obtained by Conboy and Richmond on the $\mathrm{AsPh}_{4}{ }^{+} \mathrm{BPh}_{4}{ }^{-}$electrolyte at a water/ dichloroethane (DCE) interface. Using total reflection second harmonic generation spectroscopy, they provided 'the first direct optical measurements of the accumulation' of $\mathrm{AsPh}_{4}{ }^{+}$and $\mathrm{BPh}_{4}{ }^{-}$ions in the interfacial region between the two immiscible electrolyte solutions [69]. 

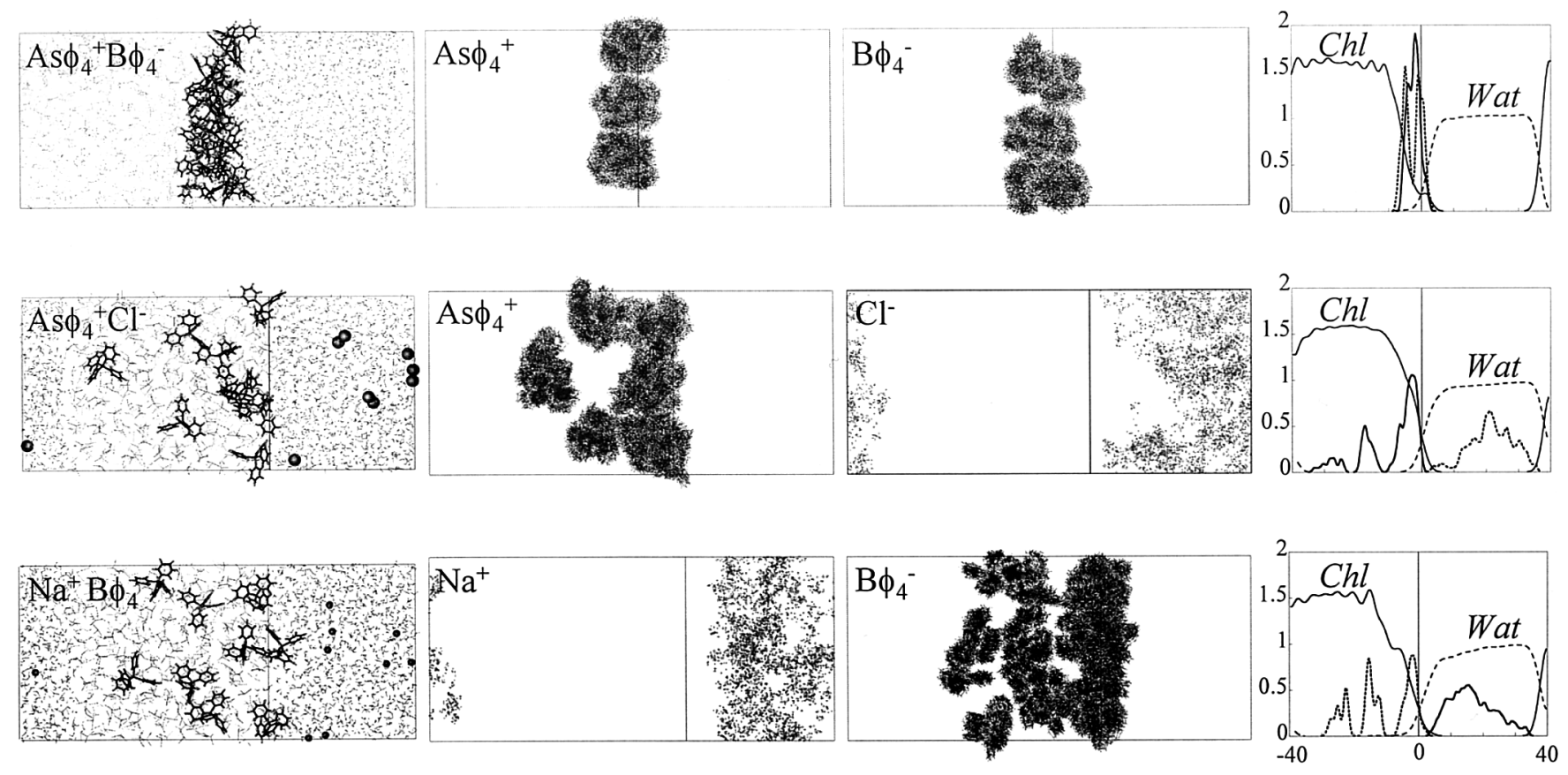

Fig. 7. The $\left(\mathrm{AsPh}_{4}{ }^{+} \mathrm{BPh}_{4}{ }^{-}\right)_{9},\left(\mathrm{Na}^{+} \mathrm{BPh}_{4}{ }^{-}\right)_{9}$ and $\left(\mathrm{AsPh}_{4}{ }^{+} \mathrm{Cl}^{-}\right)_{9}$ salts at the interface. See Figure 5 for definitions.
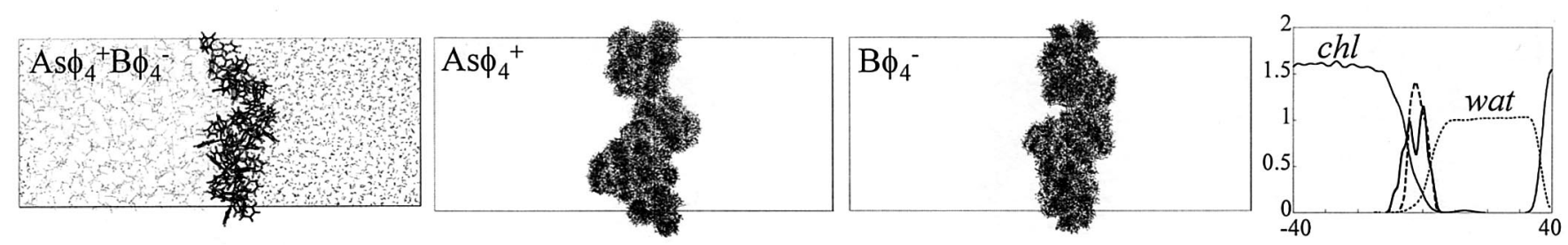

Fig. 8. The $\left(\mathrm{AsPh}_{4}{ }^{+} \mathrm{BPh}_{4}{ }^{-}\right)_{9}$ salt at the interface simulated with PME Ewald. See Figure 5 for definitions.

The $\left(\mathrm{Na}^{+} \mathrm{BPh}_{4}^{-}\right)_{9}$ and $\left(\mathrm{AsPh}_{4}^{+} \mathrm{Cl}^{-}\right)_{9}$ systems evolved differently from $\left(\mathrm{AsPh}_{4}^{+} \mathrm{BPh}_{4}^{-}\right)_{9}$. First, the $\mathrm{Na}^{+}$and $\mathrm{Cl}^{-}$ions diffused readily from the interface to the aqueous phase. Second, only about half of the $\mathrm{BPh}_{4}{ }^{-}$or $\mathrm{AsPh}_{4}{ }^{+}$ions remained at the interface, while the others diffused deeply in the chloroform phase. Departure from the interface likely results from the mutual repulsions between the $\mathrm{BPh}_{4}{ }^{-}$anions or between the $\mathrm{AsPh}_{4}{ }^{+}$cations at the interface in the absence of neutralizing counterions. This leads to the formation of electrical double layers of hydrophobic ions in chloroform or at the interface, and of hydrophilic ions immersed in water. Concerning the 'water dragging effect' [70], we notice that the organic phase of the $\left(\mathrm{AsPh}_{4}{ }^{+} \mathrm{Cl}^{-}\right)_{9}$ solution is completely dry, while in the $\left(\mathrm{Na}^{+} \mathrm{BPh}_{4}^{-}\right)_{9}$ solution, one water molecule only has followed a $\mathrm{BPh}_{4}{ }^{-}$molecule, bound via $\mathrm{O}-\mathrm{H} \cdots \pi$ interactions. These results are consistent with the KarlFischer measurements reported by Osakai et al. [71].

The interfacial $\mathrm{BPh}_{4}{ }^{-}$ions create a negative potential which attracts somewhat the $\mathrm{Na}^{+}$cations, whose proportion near the interfacial region is about $10 \%$. We suggested that this is an important feature of synergistic effects in extraction systems [34,36,37]. Not only anions of amphiphilic type (e.g. phospholipids, fatty acid carboxylates or phosphates), but also more symmetrical ones (like $\mathrm{BPh}_{4}^{-}, \mathrm{Pic}^{-}, \mathrm{ClO}_{4}^{-}$or dicarbollides [72,73]) adsorb at the interface and attract hard cations, which would be otherwise 'repelled' by the interface. This facilitates the capture of these cations by extractant molecules, which also accumulate at the interface. Electrochemical studies on the interface capacity between an organic solution of $\mathrm{NBu}_{4}^{+} \mathrm{BPh}_{4}^{-}$and an aqueous solution of $\mathrm{M}^{+} \mathrm{Cl}^{-}\left(\mathrm{M}^{+}=\mathrm{Li}^{+}\right.$to $\left.\mathrm{Cs}^{+}\right)$showed that ion pairing between $\mathrm{BPh}_{4}{ }^{-}$and $\mathrm{M}^{+}$increases from $\mathrm{Li}^{+}$ to $\mathrm{Cs}^{+}$. Thus, 'the tendency to form ion pairs at the interface is stronger, the smaller the hydration energy of the ions' [6,74]. This is consistent with the comparison of the $\mathrm{AsPh}_{4}^{+} \mathrm{BPh}_{4}^{-}$and $\mathrm{Na}^{+} \mathrm{BPh}_{4}^{-}$simulation results.

\subsection{Formation of the interface from a perfectly mixed binary solution of $\mathrm{NTMA}^{+} \mathrm{Cl}^{-}$ions}

The ion distributions reported above were obtained computationally starting from a preformed interface 

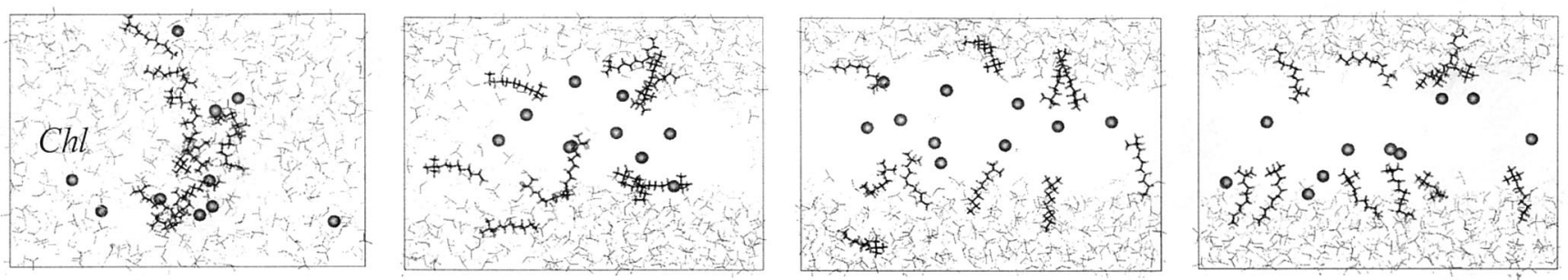

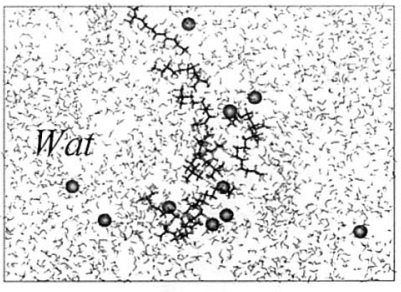

$0 \mathrm{~ns}$

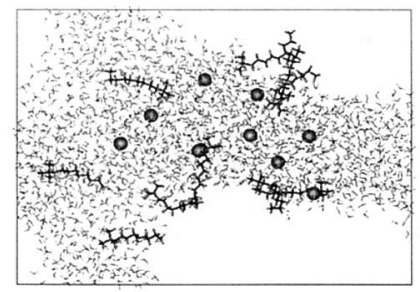

$0.2 \mathrm{~ns}$

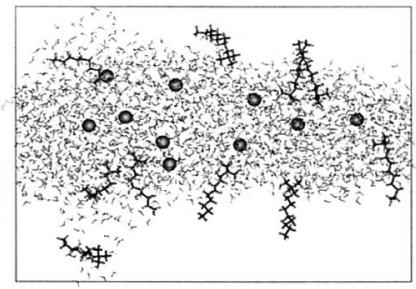

$0.3 \mathrm{~ns}$

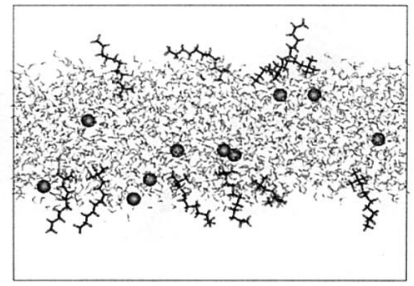

$1.5 \mathrm{~ns}$

Fig. 9. Demixing of the water/chloroform binary solution of $\left(\mathrm{NTMA}^{+} \mathrm{Cl}^{-}\right)_{10}$. Snapshots at $0,0.2,0.3$ and $1.5 \mathrm{~ns}$. Water (bottom) and chloroform (top) are shown separately, instead of superposed, for clarity.

between the water and chloroform phases. Here, we report a simulation on the phase separation between the two liquids, starting from a binary water-chloroform solution of the $10\left(\mathrm{NTMA}^{+} \mathrm{Cl}^{-}\right)$salt species (Fig. 9). The simulation starts with a perfectly mixed solution, where the solvent densities are about 0.5 for water and 0.7 for chloroform, and the salts are diluted. The extent of phase separation was followed by the $\chi_{\text {demix }}$ index, defined in Ref. [34]. This index ranges from 1.0 for perfectly mixed solutions, to 0.0 for completely separated liquids. The plot of $\chi_{\text {demix }}$ as a function of time (Fig. 10) shows a rapid exponential decay from about 0.9 to 0.3 , and that the phase separation is nearly completed at less than 200 ps. At that time, water molecules are aggregated around the $\mathrm{Cl}^{-}$hydrophilic anions, while the $\mathrm{NTMA}^{+}$cations sit at the boarder region between the two phases which start to demix. At about $400 \mathrm{ps}$, the two liquids are completely separated and the cations sit at their interface, while all $\mathrm{Cl}^{-}$anions are in water. This situation remains unchanged when the dynamics is pushed up to $1.5 \mathrm{~ns}$. It is somewhat different from the one obtained above from a preformed interface, as the interfacial area is higher, the interface being 'horizontal' instead of 'vertical'. However, as above, the $\mathrm{NTMA}^{+}$cations spread on the two formed interfaces, instead of concentrating at one only. There is thus no driving force for the spontaneous formation of a cationic monolayer, likely as a result from the cation-cation repulsions at the interface.

\section{Conclusions}

Classical molecular dynamics simulations on ion distribution at the interface between two immiscible liq- uids reveal contrasted behaviours, depending on the hydrophilic/hydrophobic balance and precise shape of the ion.

As expected, the hydrophilic $\mathrm{Na}^{+}, \mathrm{K}^{+}, \mathrm{Cl}^{-}$and $\mathrm{SCN}^{-}$ions are surrounded by water molecules only, but display different distributions with respect to the interface. The surface activity of the anions increases in the order $\mathrm{Cl}^{-}<\mathrm{SCN}^{-}<\mathrm{Pic}^{-}$, i.e. with their decreasing free energies of transfer from water to organic solvents [2]. Furthermore, their proximity with the interface depends on the counterions (compare e.g. $\mathrm{K}^{+}$ $\mathrm{Cl}^{-}$with $\mathrm{K}^{+} \mathrm{Pic}^{-}$and $\mathrm{K}^{+} \mathrm{Cl}^{-}$with $\mathrm{NTMA}^{+} \mathrm{Cl}^{-}$). The flat $\mathrm{Pic}^{-}$anions are surface active, and display specific stacking arrangements in water. The most remarkable result is the high interfacial activity of the hydrophobic $\mathrm{AsPh}_{4}^{+}$and $\mathrm{BPh}_{4}^{-}$species, which lack amphiphilic topology. As discussed in Refs. [34-36,38], two main effects facilitate adsorption at the interface. Bulky solutes do not migrate to water because the energy price to create a cavity in this liquid ('cavitation energy') [75] is too high to be compensated by the ion-water interactions. As chloroform has a surface tension lower than water $\left(27\right.$ and $72 \mathrm{mN} \mathrm{m}^{-1}$, respec-

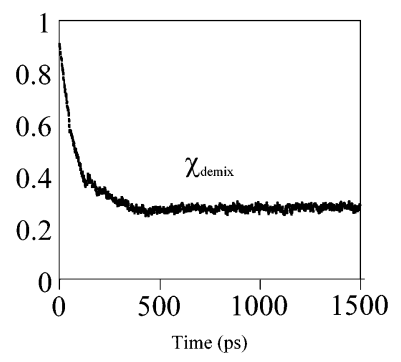

Fig. 10. Phase separation of a water-chloroform binary solution of $\left(\mathrm{NTMA}^{+} \mathrm{Cl}^{-}\right)_{10}$ The demixing index $\chi_{\text {demix }}$ is plotted as a function of time. 
tively [7]), its cavitation energy is lower and the ions should be more easily transferred to the chloroform phase. Diffusion to the organic phase does not occur, however, even with hydrophobic ions. The latter adsorb at the interface, due to electrostatic interactions and/or specific hydrogen bonding interactions with water. It is clear also that the interfaces we simulated are not saturated. Migration may thus require concentrations higher than those considered in this study. Two interesting exceptions are found, however, for the $\mathrm{AsPh}_{4}{ }^{+}$ $\mathrm{Cl}^{-}$and $\mathrm{BPh}_{4}^{-} \mathrm{Na}^{+}$systems, where adsorption of like-charged hydrophobic ions at the interface leads to diffusion of some of them to the organic phase, likely as a result of their mutual repulsions. This markedly contrasts with the isolated $\mathrm{AsPh}_{4}{ }^{+}$or $\mathrm{BPh}_{4}{ }^{-}$ions which remain at the interface during $1 \mathrm{~ns}$ of simulation [47]. Thus collective and concentration effects may critically determine the ion distribution at the interface. Similar features have been reported by Troxler and Wipff for the $\mathrm{K}^{+} \mathrm{Pic}^{-}$complex of 18-crown-6 [32].

The properties of the interface, and in particular the interfacial tension $\gamma$, are modified by the nature of the salt species. According to the Gibbs adsorption equation, a decrease of $\gamma$ compared to the neat liquid/liquid interface indicates that solutes are more concentrated at the interface than in the bulk adjacent liquid phase:

$(\partial \gamma / \partial c)_{T}=-\Gamma R T$,

where $c$ is the molar concentration, $\Gamma$ is the (algebraic) surface excess concentration, $T$ the temperature, and $R$ is the gas constant. Thus, $\gamma$ should increase with $\mathrm{K}^{+}$ $\mathrm{Cl}^{-}$solution, and decrease with solutions of $\mathrm{NTMA}^{+}$, $\mathrm{FPH}^{-}, \mathrm{AsPh}_{4}^{+}, \mathrm{BPh}_{4}^{-}$or $\mathrm{Pic}^{-}$ions, relative to the neat interface. We calculated $\gamma$ for the systems presented here and for others from Refs. [35,36], but found high fluctuations and some inconsistencies in the results. We looked at other features of the surface, like the orientation of the water dipoles, number of hydrogen bonds per water molecule, or diffusion coefficient of water molecules. No marked trend was found concerning these data, which will be reported later.

Concerning the phase separation, these simulations, as previously reported ones [34-37], confirm that it is a very fast process. At the microscopic level, water and 'oil' are never completely mixed, as separation occurs in less than $1 \mathrm{~ns}$. This demonstrates the importance of interfacial phenomena in heterogeneous systems and in assisted ion extraction processes. As the extractant and its cation complex are surface active, ion capture and recognition have to take place at the interface. Thus, any factor which enhances the concentration of these species at the interface should facilitate the ion extraction. In particular, adsorption of lipophilic anions at the interface increases the cation concentration in this region. This is consistent with electrochemical measurements on ion transfer with different counterions [76].
Beyond the systems studied, it is suggested that hydrophobic ions, 'expelled by water', should accumulate at other aqueous interfaces like the interface with polymeric species, in ion-exchangers or in supported liquid membranes. This should obviously be the case for ion complexes with ionophores which form bulky hydrophobic species. At liquid-water interfaces involving liquids of surface tension higher than water, the reversed behaviour is expected, as shown by the accumulation of cation cryptates at a water/mercury interface [77].

Generally speaking, it would be desirable to prove how the simulated systems are 'close to the reality'. This is a difficult task. Microscopic insights can be obtained from surface spectroscopy measurements of the adsorbed species, when possible. To our knowledge, there are no consistent set data to be compared with our simulations. Surface tension measurements provide valuable trends in surface activities, but their interpretation in terms of microscopic ion distribution rests on models. Thus, computational results can be presently assessed mostly from comparisons with computations using alternative models. Several aspects have been addressed in previous papers (see e.g. Refs. [25,38]). Based on our experience on interfacial systems with ions and/or ionophores, similar conclusions concerning the size of the interface and the interfacial distribution of solutes could be obtained when the system was modelled with 2D/3D periodicity, Ewald/no-Ewald, with different starting configurations (provided that the sampling is long enough), and with different empirical representation of the chloroform phase (standard OPLS/scaled OPLS/all atom + polarization models). Given the importance of electrostatic forces, it will however be necessary to develop refined solvent models including polarization and many body effects in conjunction with improved treatments of boundaries, in order to better account for the interactions between the two liquid phases as well as with ionic solutes (see e.g. Refs. [16,78]).

Computations are expected to become of increasing importance to understand the solvation features of charged species in heterogeneous environments and near the surface of liquids. Increasing the size and complexity of the simulated systems will allow to fill the gap between organized interfacial systems (membranes, monolayers, bilayers,...) and supramolecular arrangements like micelles or liquid crystals. Methodological improvements should concern the representation of the potential energy of the system (short range and long range electrostatics, including polarization and many body contributions to the potential energy), the size and complexity of the simulated system and the simulated times. Complex interfacial processes like phase transfer catalysis, ion capture, electron or energy transfer, will be challenges for promising techniques like mixed MM/QM methods which are presently developed [79]. 


\section{Acknowledgements}

The authors are grateful to CNRS-IDRIS and to Université Louis Pasteur for allocation of computer resources. FB and RS thank the French Ministry of Research for a grant. GW thanks EEC (F14W-CT960022 contract) and PRACTIS for support.

\section{References}

[1] A.G. Volkov, D.W. Deamer, D.L. Tanelian, V.S. Markin, Liquid Interfaces in Chemistry and Biology, Wiley, New York, 1998, p. 551.

[2] H.H. Girault, D.J. Schiffrin, Electrochemistry of Liquid/Liquid Interfaces, in: A.J. Bard (Ed.), Electroanalytical Chemistry, Marcel Dekker, New York, 1989, pp. 1-141 and references cited therein.

[3] V.E. Kazarinov, The Interface Structure and Electrochemical Processes at the Boundary Between two Immiscible Liquids, Springer, Berlin, 1987, pp. 179-205 and references cited therein.

[4] L.I. Osipow, Surface Chemistry. Theory and Industrial Applications, ACS, Reinhold, New York, 1962.

[5] H. Watarai, Trends Anal. Chem. 12 (1993) 313.

[6] W. Schmickler, Interfacial Electrochemistry, Oxford University Press, New York, 1996, p. 288.

[7] A.W. Adamson, Physical Chemistry of Surfaces, fifth ed., Wiley, New York, 1990.

[8] J. Koryta, Ion Selective Electrode Rev. 5 (1983) 131.

[9] K.B. Eisenthal, Chem. Rev. 96 (1996) 1343.

[10] P.F. Brevet, Surface Second Harmonic Generation, Cahiers de Chimie, Presses Polytechniques et Universitaires Romandes, 1997.

[11] S.A. Rice, Nature 316 (1985) 108. P.S. Pershan, Faraday Discuss. Chem. Soc. 89 (1990) 231.

[12] M.P. Allen, D.J. Tildesley, in: W.F. van Gunsteren, P.K. Weiner (Eds.), Computer Simulation of Liquids, Clarendon, Oxford, 1987.

[13] E. Clementi, Determination of Liquid Water Structure, Coordination Numbers for Ions and Solvation for Biological Molecules, Springer, Berlin, 1976.

[14] R.W. Impey, P.A. Madden, I.R. McDonald, J. Phys. Chem. 87 (1983) 5071.

[15] L. Troxler, G. Wipff, J. Am. Chem. Soc. 116 (1994) 1468.

[16] T.-M. Chang, L.X. Dang, J. Phys. Chem., Sect. B 101 (1997) 10518. T.-M. Chang, K.X. Dang, K.A. Peterson, J. Phys. Chem., Sect. B 101 (1997) 3413. T.-M. Chang, K.A. Peterson, L.X. Dang, J. Chem. Phys. 103 (1995) 7502.

[17] R.W. Impey, M. Sprik, M.L. Klein, J. Am. Chem. Soc. 109 (1987) 5900.

[18] J.-C. Soetens, C. Millot, B. Maigret, J. Phys. Chem., Sect. A 102 (1998) 1055.

[19] T. Matsui, W.L. Jorgensen, J. Am. Chem. Soc. 114 (1992) 3220.

[20] G.M. Torrie, J.P. Valleau, J. Electroanal. Chem. 106 (1986) 69.

[21] K. Heinzinger, Pure Appl. Chem. 57 (1985) 1031.

[22] E. Spohr, K. Heinzinger, Electrochim. Acta 33 (1988) 1211.

[23] I. Benjamin, Science 261 (1993) 1558.

[24] I. Benjamin, Acc. Chem. Res. 28 (1995) 233 and references cited therein.

[25] I. Benjamin, Annu. Rev. Phys. Chem. 48 (1997) 407 and references cited therein.
[26] S. Bandyopadhyay, J.C. Shelley, M. Tarek, P.B. Moore, M.L. Klein, J. Phys. Chem., Sect. B 102 (1998) 6318.

[27] A.R. van Buuren, S.-J. Marrink, J.C. Berendsen, Colloids Surf. 102 (1995) 143.

[28] G. Wipff, M. Lauterbach, Supramol. Chem. 6 (1995) 187.

[29] G. Wipff, E. Engler, P. Guilbaud, M. Lauterbach, L. Troxler, A. Varnek, New J. Chem. 20 (1996) 403.

[30] A. Varnek, L. Troxler, G. Wipff, Chem. Eur. J. 3 (1997) 552.

[31] P. Beudaert, V. Lamare, J.-F. Dozol, L. Troxler, G. Wipff, Solv. Extract. Ion Exch. 16 (1998) 597.

[32] L. Troxler, G. Wipff, Anal. Sci. 14 (1998) 43.

[33] M. Lauterbach, Thesis, Université Louis Pasteur, Strasbourg, 1997.

[34] N. Muzet, E. Engler, G. Wipff, J. Phys. Chem., Sect. B 102 (1998) 10772.

[35] F. Berny, N. Muzet, R. Schurhammer, L. Troxler, G. Wipff, MD simulations on ions and ionophores at a liquid/liquid interface: from adsorption to recognition, in: NATO ARW Athens, in: G. Tsoucaris (Eds.), Current Challenges in Supramolecular Assemblies, Kluwer, Dordrecht, 1998, pp. $221-248$.

[36] F. Berny, N. Muzet, L. Troxler, G. Wipff, Simulations of liquid-liquid interfaces: a key border in supramolecular chemistry, in: R. Ungaro, E. Dalcanale (Eds.), Supramolecular Science: Where it is and Where it is Going, Kluwer, Dordrecht, 1999, pp. 95-125.

[37] M. Baaden, F. Berny, N. Muzet, L. Troxler, G. Wipff, Interfacial features of assisted liquid-liquid extraction of uranyl and cesium salts: a molecular dynamics investigation, in: G. Lumetta, R. Rogers, A. Gopolan (Eds.), Calixarene for Separation, ACS Symp. Ser. 757, New York, 2000, pp. 71-85. M. Baaden, F. Berny, G. Wipff, The chloroform/TBP/aqueous nitric acid interfacial system: a molecular dynamics investigation, J. Mol. Liquids (2000) in press.

[38] M. Lauterbach, E. Engler, N. Muzet, L. Troxler, G. Wipff, J. Phys. Chem., Sect. B 102 (1998) 225.

[39] P. Guilbaud, G. Wipff, New J. Chem. 20 (1996) 631.

[40] F. Arnaud-Neu, S. Barboso, F. Berny, A. Casnati, N. Muzet, A. Pinalli, R. Ungaro, M.J. Schwing-Weil, G. Wipff, J. Chem. Soc., Perkin Trans 2 (1999) 1727.

[41] M. Lauterbach, G. Wipff, Liquid-Liquid Extraction of Alkali Cations by Calix[4]crown Ionophores: Conformation and Solvent Dependent $\mathrm{Na}+/ \mathrm{Cs}+$ Binding Selectivity: A MD FEP study in pure Chloroform and MD Simulations at the Water/ Chloroform Interface, in: L. Echegoyen, A. Kaifer (Eds.), Physical Supramolecular Chemistry, Kluwer, Dordrecht, 1996, pp. 65-102.

[42] A. Porquet, G. Wipff, MD simulations of phospholipids in water: toward aggregation and formation of vesicles, in: F. Bernardi, J.-L. Rivail (Eds.), 1st European Conference on Computational Chemistry, AIP, Nancy, 1994, p. 388.

[43] M.G. Cacace, E.M. Landau, J.J. Ramsden, Quarterly Rev. Biophys. 30 (1997) 241.

[44] K.E. Koenig, G.M. Lein, P. Stuckler, T. Kaneda, D.J. Cram, J. Am. Chem. Soc. 101 (1979) 3553.

[45] G. Pozzi, V. Birault, B. Werner, O. Dannenmuller, Y. Nakatani, G. Ourisson, S. Terakawa, Angew. Chem., Int. Ed. Engl. 35 (1996) 177.

[46] Y. Marcus, J. Chem. Soc., Faraday Trans. 1 (1987) 2985.

[47] R. Schurhammer, G. Wipff, New J. Chem. (1999) 381.

[48] D.A. Case, D.A. Pearlman, J.C. Caldwell, T.E. Cheatham III, W.S. Ross, C.L. Simmerling, T.A. Darden, K.M. Merz, R.V. Stanton, A.L. Cheng, J.J. Vincent, M. Crowley, D.M. Ferguson, R.J. Radmer, G.L. Seibel, U.C. Singh, P.K. Weiner, P.A. Kollman, AMBER5, University of California, San Francisco, 1997. 
[49] L. Troxler, J.M. Harrowfield, G. Wipff, J. Phys. Chem. 102 (1998) 6821.

[50] J. Åqvist, J. Phys. Chem. 94 (1990) 8021.

[51] T.P. Lybrand, J.A. McCammon, G. Wipff, Proc. Natl. Acad. Sci. USA 83 (1986) 833.

[52] Spartan. 4.0, Wavefunction Inc. (1995).

[53] W.L. Jorgensen, J. Chandrasekhar, J.D. Madura, J. Chem. Phys. 79 (1983) 926.

[54] W.L. Jorgensen, J.M. Briggs, M.L. Contreras, J. Phys. Chem. 94 (1990) 1683.

[55] X. Daura, P.H. Hünenberger, A.E. Mark, E. Querol, F.X. Avilés, W.F. van Gunsteren, J. Am. Chem. Soc. 118 (1996) 6285.

[56] G. Hummer, L.R. Pratt, A.E. Garcia, J. Phys. Chem. 100 (1996) 1206.

[57] I.G. Tironi, R. Sperb, P.E. Smith, W.F. van Gunsteren, J. Chem. Phys. 102 (1995) 5451

[58] P.P. Ewald, Ann. Phys. 64 (1921) 253.

[59] J. Hautman, M.L. Klein, Mol. Phys. 75 (1992) 379.

[60] T.A. Darden, D.M. York, L.G. Pedersen, J. Chem. Phys. 98 (1993) 10089.

[61] K.D. Collins, M.W. Washabaugh, Quater. Rev. Biophys. 18 (1985) 323

[62] A. Frumkin, Z. Physik. Chem. 109 (1924) 34.

[63] N.L. Jarvis, M.A. Scheiman, J. Phys. Chem. 72 (1968) 74.

[64] J.E. Randles, Discuss. Faraday Soc. 24 (1957) 194.

[65] G. Wipff and L. Troxler, MD simulations on synthetic ionophores and on their cation complexes: comparison of aqueous/non-aqueous solvents, in: G. Wipff (Ed.), Computational Approaches in Supramolecular Chemistry, NATO ASI Series; Kluwer, Dordrecht, 1994, pp. 319-348.
[66] K.J. Schweighofer, I. Benjamin, J. Phys. Chem. 99 (1995) 9974 [67] I. Dance, M. Scudder, Chem. Eur. J. 2 (1996) 481.

[68] I. Dance, M. Scudder, J. Chem. Soc., Dalton Trans. (1996) 3755.

[69] J.C. Conboy, G.L. Richmond, J. Phys. Chem., Sect. B 101 (1997) 983.

[70] W. Fan, R.-S. Tsai, N. El Tayar, P.-A. Carrupt, B. Testa, J. Phys. Chem. 98 (1994) 329.

[71] T. Osakai, A. Ogata, K. Ebina, J. Phys. Chem., Sect. B 101 (1997) 8341.

[72] J. Rais, S. Tachimori, J. Radioanal. Nucl. Chem. Lett. 188 (1994) 157.

[73] J. Rais, S. Tachimori, P. Selucky, K. Kadlecova, Separ. Sci. Technol. 29 (1994) 261.

[74] C. Yufei, V.J. Cunnane, D.J. Schriffin, L. Mutomäki, K. Kontturi, J. Chem. Soc., Faraday Trans. 87 (1991) 107.

[75] R.A. Pierotti, Chem. Rev. 76 (1976) 717.

[76] A.N. Popov, Counterions and adsorption of ion-exchange extractants at the water/oil interface, in: V.E. Kazarinov (Ed.), The Interface Structure and Electrochemical Processes at the Boundary Between two Immiscible Liquids, Springer, Berlin, 1987, pp. 179-205 and references cited therein.

[77] M. Carlà, C.M.C. Gambi, P. Baglioni, J. Phys. Chem. 100 (1996) 11067.

[78] I. Benjamin, Chem. Phys. Lett. (1998) 480. V.P. Sokhan, D.J. Tildesley, Faraday Discuss. 104 (1996) 193.

[79] M.A. Thompson, E.D. Glendening, D. Feller, J. Am. Chem. Soc. 116 (1994) 10465. J. Gao, T.R. Furlani, Comput. Chem. (1995) 24.

[80] M.A. Wilson, A. Polnorille, J. Chem. Phys. 95 (1991) 6005. 